\title{
Projetar a Forma: uma proposta de ferramenta metodológica para o direcionamento da sintaxe visual no design de moda
}

\author{
Sanches, Maria Celeste de F ${ }^{\mathrm{a}}$; Hernnadis-Ortuño, Bernabéb \& Martins, Sérgio R. M. \\ ${ }^{a}$ FAU-Universidade de São Paulo \& Universitat Politècnica de València, Brasil-España, tsanches@sercomtel.com.br, \\ ${ }^{\mathrm{b}}$ Universitat Politècnica de València, España, bhernandis@degi.upv.es, \\ cFaculdade de Arquitetura e Urbanismo da Universidade de São Paulo, Brasil, sergiore@usp.br,
}

\begin{abstract}
Resumo
O artigo apresenta o recorte de uma pesquisa de doutoramento desenvolvida em parceria entre Universidade de São Paulo, Universitat Politècnica de València and Universidade Estadual de Londrina. Aborda o âmbito do ensino de projeto em graduações de design de moda, com ênfase na investigação de metodologias para gerir o processo projetual, propondo estratégias facilitadoras da sintaxe visual para a configuração de artefatos de vestuário de moda. Para isso, parte de uma pesquisa exploratória, de base bibliográfica e documental, em que se analisa o sistema de interações construído entre vestimenta e usuário, para demonstrar que as relações estabelecidas no sistema corpo-artefatoambiente se distribuem em fatores de adaptação física, expressão individual e representação social. Deste modo, situa o vestuário de moda como um espaço de vivências sensoriais que produz significações e enfatiza a dimensão estético-simbólica como quesito essencial no planejamento da experiência de uso deste tipo de produto. Tal perspectiva corrobora a relevância de ferramentas metodológicas que propiciem a síntese de códigos expressivos para guiar a composição formal, com vistas à articulação entre as dimensões material e informacional do artefato projetado, uma vez que a informação (conteúdo) é transmitida pela sintaxe dos elementos da configuração (forma). Sobre esta plataforma, o artigo relata as bases teóricas, a proposição e a aplicação de uma ferramenta destinada à geração de conceitos formais na prática projetual do design de moda. A explanação integra fundamentos acerca do design de moda, do pensamento visual e das técnicas de sintese imagética, para examinar apreciações em campo e discutir a efetividade da referida ferramenta. Os resultados reforçam a hipótese de que a combinação de métodos que exploram o pensamento visual pode auxiliar os estudantes na percepção das diversas variáveis que influenciam a composição formal de um produto e, por conseguinte, na sintese de relações sintático-semânticas para impulsionar a geração formal.
\end{abstract}

Palavras-chave: design de moda, projeto, metodologia, ensino, sintese visual. 
Projectar a forma: uma proposta de ferramenta metodológica para o direccionamento da sintaxe visual no design de moda,

\begin{abstract}
This article presents a part of a PhD research developed in partnership between the Universidade de São Paulo, Universitat Politècnica de València and Universidade Estadual de Londrina. It approaches the sphere of project teaching in undergraduate fashion design courses, with an emphasis on research of methodologies developed to manage the design process, proposing facilitating strategies of visual syntax for the configuration of fashion clothing artifacts. To achieve this, It was applied a part of the exploratory bibliographical and documental research, which examines the interaction system built between clothing and user to demonstrate that the relations established in the body-artifact-environment system are distributed on factors of physical adaptation, individual expression and social representation. Thus, it situates the fashion clothing as a field of sensory experiences that produces meanings and emphasizes the aesthetic and symbolic dimension as an essential requirement in the planning of user experience in this type of product. Such perspective reinforces the relevance of methodological tools which propitiate the synthesis of expressive codes in order to guide the formal composition with regard to the links between the materials and informational dimensions of the designed artifact once the information (content) is transmitted by the syntax of the elements of configuration (form). Upon this platform, this article reports the theoretical basis, the proposition and application of a tool aimed to generate formal concepts in the project practices of fashion design. The explanation integrates fundaments of fashion design, visual thinking and imagery synthesis techniques to examine field assessments and discuss the effectiveness of this tool. The results reinforce the hypothesis that the combination of methods that explore the visual thinking can help students in the perception of the different variables that influence the formal composition of a product and therefore the synthesis of syntactic-semantic relations to boost the formal generation.
\end{abstract}

Keywords: fashion design, design, methodology, teaching, visual synthesis.

\title{
1. Introdução
}

Todo projeto de design se vincula às solicitações do contexto sociocultural, propondo interfaces (tangíveis ou intangíveis) que mediam a integração humana com esse entorno. Por isso, a definição de referenciais simbólicos para a configuração de um artefato depende do estudo dos códigos comunicativos que permeiam o contexto, já que tal objeto deve fazer parte do sistema de sinais sociais presentes no universo do usuário.

Para projetar o vestuário de moda é preciso entendê-lo como um espaço dinâmico e interativo, no qual os elementos que compõe sua forma mediam um enunciado não verbal que se integra às mensagens do meio onde se insere, promovendo um processo de identificação e comunicação. Assim, ao abordar o projeto de design na área de moda, é essencial analisar a articulação de valores simbólicos como um ponto crucial entre as diretrizes do ensino de projeto. Por conseguinte, o desenvolvimento de ferramentas para auxiliar o desenvolvimento da capacidade expressiva é fundamental para a formação de um designer de moda, 
uma vez que o refinamento desta habilidade o ajudará na decodificação e transposição de códigos estético-simbólicas para a configuração de produtos de moda.

Nesta direção, este artigo relata os resultados parciais de uma investigação de doutoramento que aborda o instrumental metodológico para o o ensino de projeto. No presente estudo, foi realizado uma investigação em campo para verificar o desempenho de estratégias metodológicas para a síntese de conceitos de linguagem visual no projeto de vestuário de moda. As interações em campo foram efetuadas com estudantes do curso de Design de Moda da Universidade Estadual de Londrina (UEL), por meio da observação participante em oficinas de projeto.

A argumentação pontua a importância da síntese visual como facilitadora do pensamento projetual. Desta maneira, sintetiza as bases teóricas que, agregadas às análises da observação participante em campo, guiaram a proposição de um instrumental metodológico que auxilia a síntese de conceitos expressivos para a sintaxe da forma no design de moda.

Cabe observar que no universo pedagógico estudado a expressão utilizada para referir-se ao campo da gestão do projeto de artefatos de vestuário de moda foi convencionada como "design de moda", por isso adotou-se a mesma nomenclatura para a presente reflexão. Destaca-se também que algumas análises contidas no texto já foram publicadas em trabalho anterior, no entanto, como integram a trajetória de uma pesquisa mais ampla, são fundamentais para o entendimento da proposta aqui tratada.

\section{Bases Teóricas}

O valor de um artefato está intimamente ligado à avaliação subjetiva do seu desempenho na relação de uso, ou seja, um produto será considerado bom à medida que estabeleça algum significado no cotidiano de seu usuário. "Algo deve ter forma para ser visto, mas deve fazer sentido para ser compreendido e utilizado" (Krippendorff, 1989, p.14). Para tanto, se presume que os enunciados visuais transmitidos através da configuração de um artefato podem gerar percepções de natureza diversificada, evidências sobre a operacionalidade, o uso, referências culturais, etc. Tais percepções, quando sobrepostas pelo usuário em seu contexto sociocultural, são assimiladas e interpretadas, derivando decodificações que compõem o conteúdo simbólico do artefato. Assim, a ordenação configurativa é suporte da informação e essencial na semântica do produto.

A configuração (forma) do vestuário de moda é concretizada e refinada ao longo do processo projetual, a partir da análise e experimentação integrada de aspectos perceptivos, materiais e técnicos, todavia essa efetivação depende da delimitação de critérios norteadores para impulsionar a sua geração. Neste sentido, as bases teóricas, resumidas a seguir, assinalam os aspectos comunicativos do vestuário de moda e a importância deste quesito no seu processo projetual.

\subsection{O Vestuário de Moda como Enunciado Visual}

O vestuário de moda participa ativamente das vivencias humanas com o entorno físico e sociocultural. Como veículos de adaptação física, expressão individual e representação social, as vestes se convertem em instrumentos para a construção de significações e registros móveis das relações de tempo-espaço incorporadas à cultura material.

A vestimenta, conforme Montemezzo e Santos (2002), pode ser considerada como "Interface Global Primária", visto que se faz presente na maior parte do tempo cotidiano, incorpora-se ao meio físico/material do homem e interage com o organismo de maneira generalizada e direta, intervindo na realização das ações humanas e no relacionamento do corpo com quaisquer espaços. Seguindo por esta 
Projectar a forma: uma proposta de ferramenta metodológica para o direccionamento da sintaxe visual no design de moda,

direção, destaca-se Saltzman (2008) e Souza (2008) que exploram os conceitos de habitat, interioridade e exterioridade, espaço público e privado, para explicar que a superfície têxtil, ao delimitar forma, volume e silhueta, simultaneamente, transforma a anatomia corpórea, promove interfaces com o espaço circundante e configura um espaço particular de sensações e percepções que se antepõe às relações com outros espaços e outros corpos. Deste modo, pode-se visualizar o vestuário como segunda pele, integrando um conjunto de camadas espaciais sucessivas, em que interagem espaço corpóreo, espaço da veste e os espaços por onde este corpo vestido transita e habita.

Consequentemente, corpo e artefato entrelaçados se acoplam a outros espaços, onde outros corpos vestidos transitam e se integram (mesmo que temporariamente), criando uma malha comunicativa que manifesta um ininterrupto e recíproco movimento de transformação do cenário social. No contexto complexo atual, marcado pela realidade multifacetada, híbrida e dinâmica, as significações geradas nessa malha de percepções são transitórias, por isso, cada corpo habitante transforma o espaço habitado, mas também é constantemente transformado neste fluxo rizomático de conexões.

Desta perspectiva, o vestuário de moda é um importante veículo de processos comunicativos, uma linguagem, como sancionam Castilho (2004) e Oliveira (2007), sobretudo pelo canal visual não verbal. Isso conduz, naturalmente, a presente explanação pelos caminhos da comunicação visual, inferida no presente contexto como o processo de interação entre signos não linguísticos, especificamente os que se pronunciam na composição plástica da forma visual de artefatos. Coelho (2008) recomenda que este tipo de comunicação, quando estudado em função do projeto de um artefato, deve ser considerado como um dos propósitos inerentes ao design, definindo que projetar a comunicação visual significa "estabelecer qual a melhor maneira de transmitir visualmente um determinado conteúdo" (Coelho, 2008, p.142). Contudo, o autor enfatiza os elementos culturais como determinantes dos significados possíveis para as diversas formas visuais de comunicação.

Para analisar a vestimenta como veículo comunicativo, retoma-se os componentes de uma mensagem visual não verbal definidos por Munari (2006): informação e suporte visual, sendo a informação o conteúdo a ser comunicado e o suporte visual a forma. Nesta linha de raciocínio, o conteúdo semântico do artefato se faz perceptível através do conjunto de elementos e relações compositivas que constituem sua forma.

No campo do design, Cardoso (2012) argumenta que o termo forma abrange três aspectos interrelacionados inseparáveis: a) aparência, aspecto perceptivo por um olhar; b) configuração, no sentido composicional, de arranjo das partes; c) estrutura, referente à dimensão construtiva. Neste sentido, atribuise à forma de um objeto uma qualidade sensorial ampliada, que não se percebe em um único plano de visualização. Para percebê-la há uma confluência de aspectos de superfície, volumetria, contorno, espaço e ponto de vista. Como entidade de dimensões múltiplas e interdependentes, o autor destaca o papel expressivo e informacional da forma, produzido especialmente pela percepção visual.

Sob este prisma, encontra-se pertinência com o que Couto, Farbiarz e Novaes (2014) denomina figura, definida pelo autor como o resultado do processo de configurar um objeto, sendo o conjunto de aspectos do objeto que se pode perceber sensorialmente, imaginar e representar.

Assim, o termo forma, neste estudo, é entendido como um composto material/estético /informacional. Compreende o conjunto de relacionamentos entre os componentes configurativos de um artefato, experimentado sensorialmente em múltiplas dimensões e percebido como expressão de informação visual. Logo, forma e configuração, quando usados como atributo de artefato (produto) no decorrer do texto, têm o mesmo sentido. 
Entretanto, para estabelecer um canal de comunicação, através da forma do vestuário de moda, é fundamental projetar de modo coerente a ordenação (sintaxe) dos elementos configurativos, para que esta se integre ao fluxo de códigos vigentes no contexto do usuário e, por conseguinte, sejam reconhecidos, assimilados e, finalmente construídos como valores simbólicos. É certo que, para isso, é necessário codificar o artefato em sistemas de signos reconhecíveis, pelo que se prevê que é imperativo antes identificá-los entre as unidades culturais presentes no contexto em que o produto será inserido.

Niemeyer (2003) explica que esse processo de comunicação envolve dois elementos ativos: gerador (designer/empresa) e interpretador (usuários e sujeitos que não são usuários finais, mas estão implicados no trajeto da mensagem, na comercialização e difusão). Para a autora, gerador e interpretador alternam suas posições, pois com sua reação, “o interpretador passa a produzir mensagens, que por sua vez são processadas (ou não) pelo gerador" (Niemeyer, 2003, p.23). Desta maneira, o designer absorbe grande parte da responsabilidade pela a escolha das estratégias comunicacionais do projeto.

Toda a arguição anterior demonstra a estreita relação entre as dimensões sintática e semântica de um produto. No entanto, para a efetiva transposição de conteúdo (informação) para a forma, é essencial compreender os conceitos de sintaxe e semântica entre as dimensões atuantes na configuração de um produto. Estas dimensões foram explicadas por Niemeyer (2003), juntamente com as dimensões material e pragmática, conforme resumido a seguir.

A) Dimensão material: se constitui pelas propriedades materiais do artefato, a sua materialidade em si. Niemeyer não a explora isoladamente, salientando que o aspecto hílico será melhor entendido como elemento comunicativo quando articulado com as outras dimensões.

B) Dimensão sintática: referente à estrutura e ao funcionamento técnico do artefato. A estrutura consiste na parte do produto e o modo como se conectam, incluindo construção técnica e detalhes visuais, os quais também são descritos como aspectos da composição formal, que abrange elementos visuais compositivos e procedimentos relacionais. Gomes (2006) também elucida esta dimensão sob o mesmo princípio de ordenação dos elementos que se articulam para formar e informar.

C) Dimensão pragmática: versa sobre o uso prático (utilidade) do produto, considerando todo o seu ciclo de vida, apreende o conjunto de relações que o produto estabelece com o usuário no campo ergonômico ou sociológico (quem usa e em que situação é usado). Gomes (2006) destaca que envolve a relação entre os signos (produto) e seus intérpretes (usuários).

D) Dimensão semântica: concentra as qualidades expressivas e representacionais, é a dimensão que agrega aspectos de referência à dimensão sintática e material, seus descritores. Trata de como o produto sugere, através da composição formal, as suas qualidades de uso.

É primordial advertir que, tais dimensões foram isoladas para fins didáticos, mas Niemeyer (2003) alerta que as dimensões se constituem simultaneamente e articulam qualidades representacionais em conjunto, uma vez que os significados são cunhados por meio da percepção conjugada de tais dimensões, mediante a experiência vivenciada com o produto em um determinado contexto. Por consequência, ainda que esta pesquisa esteja centralizada no recorte que trata da dimensão sintática e de sua influência na dimensão semântica, a composição da forma do vestuário é resultante da coordenação das propriedades da matéria, dos requisitos de uso, dos referenciais estético-simbólicos e dos parâmetros de adaptação para o conforto corporal. Somente por meio da interação desses fatores é que se expressa alguma informação coerente.

Portanto, o sucesso da comunicação está diretamente ligado à habilidade do gerador (designer/empresa) do enunciado formal/visual em manipular os elementos sintáticos na configuração dos produtos. Sanches (2012) confirma que a competência para manejar a linguagem visual é indispensável aos designers que 
pretendem articular códigos simbólicos no planejamento das interfaces que projetam, proporcionando experiências cognitivas a partir do uso de tais artefatos.

Para que a forma seja mediadora de significações, o processo projetual se encarrega de antever relações semânticas que possam ser atribuídas ao artefato nos contextos a que se destinam. No entanto, essa tarefa só obterá êxito se for auxiliada pelo conhecimento de diretrizes para organizar e harmonizar os elementos formais, extraindo-os do entorno e transpondo-os para o planejamento do partido comunicacional do artefato. Com o intuito de proporcionar meios para estabelecer tais diretrizes, examina-se o processo de delimitação projetual no design de moda.

\subsection{O Projeto do Vestuário de Moda}

Segundo Niemeyer (2003) o modo como um produto é sentido decorre do julgamento de percepção que é submetido. Então, face a sua estrutura mental, o indivíduo pode reagir ao produto. No projeto de design de moda, analisando a relação entre usuário e produto, infere-se que a percepção da informação depende de uma sintaxe que relaciona elementos compositivos em códigos reconhecíveis, dando forma ao conteúdo. Logo, como já comentado, a definição de um referencial simbólico (códigos reconhecíveis) depende do estudo do contexto sociocultural, já que deve fazer parte do sistema de sinais sociais presentes no universo do usuário.

Sanches, Hernandis e Martins (2015) ressaltam que o vestuário de moda traz intrínseco um propósito de uso social, para o qual a experiência sensória é o veículo. Por isso, ao planejar esta interface vestível, é premente considerar que a experiência do corpo usuário unifica percepções em nível físico, psicológico e social. O sistema de interações entre usuário, vestimenta e ambiente, vincula-se à adaptação do corpo ao entorno, atribuindo-lhe proteção e, especialmente, uma aparência propícia para a aceitação e integração no contexto sociocultural.

Dos argumentos supracitados se extrai dois princípios básicos para a delimitação da forma no design de moda: a) cada elemento configurativo é um enunciado visual e, concomitantemente, meio de adaptação física ao ambiente material; b) o enunciado visual da forma é altamente influenciado por conteúdos culturais.

Deste modo, o processo projetual emerge das solicitações do contexto e finaliza submergindo outra vez na mesma realidade que o definiu, transformando-a e, possivelmente, influenciando novas solicitações. Então, é essencial conhecer que tipo de informações definem as variáveis projetuais e também as interações geradas pelo artefato projetado.

Para maior entendimento dos fatores que influenciam a delimitação de um conceito de linguagem no design de moda, destaca-se os pontos cruciais do desenvolvimento projetual e o fluxo de variáveis envolvidas neste setor. Nesta direção, Sanches (2011) e Sanches et al. (2016) resumem as principais categorias de informação que direcionam o projeto do vestuário de moda, mostrando a relevância da inserção do projeto no seu contexto gerador e destinatário, para a efetiva integração das demandas humanas, sistemas produtivos e gestão empresarial. Os autores definem o fluxo de informações entre os universos usuário e corporativo, elencando as variáveis fundamentais para a delimitação projetual no design de moda (Fig.1). 


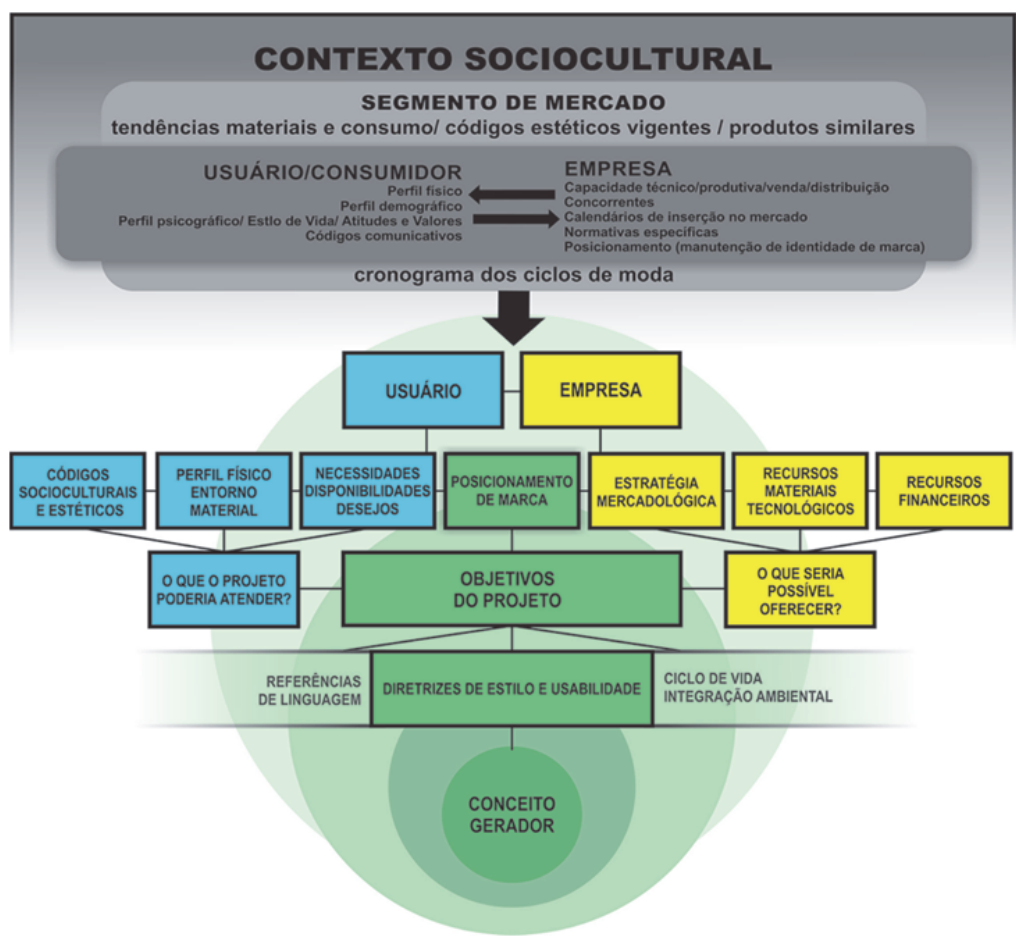

Fig.1 - Fluxo de informações na delimitação projetual do Design de Moda. Fonte: Elaborado pela autora, com base em Sanches (2011) Sanches et al. (2016)

Sanches (2011) exalta que esta organização não é uma cadeia linear de procedimentos, mas sim uma estrutura dinâmica que se entrelaça, se retroalimenta e absorve novas informações que a transformam. "Contudo, o ponto de partida é sempre o reconhecimento do cenário que envolve o usuário, das nuances deste contexto, para a identificação das suas necessidades e desejos. " (Sanches, 2011, p.2). Por consequência a delimitação projetual parte da interpretação e decodificação do contexto para sintetizar as diretrizes do projeto e o conceito gerador.

Esclarecendo, para Lessa (2009), o conceito do artefato refere-se a uma síntese dos traços e características do artefato que mais fundamentalmente o determinam, sua essência de atuação no cotidiano humano. Neste sentido, adotou-se o termo "conceito gerador", à semelhança de Montemezzo (2003) e Sanches (2012), destacando que projetos de vestuário de moda geralmente englobam a concepção de vários artefatos em concomitância, vinculados por uma mesma ideia central. Essa essência partilhada guia os princípios funcionais/formal/visual do conjunto de artefatos projetados, respeitando a imagem da marca $\mathrm{e}$ as metas comerciais da empresa que propõe os novos produtos e/ou serviços. A diretriz expressa pelo conceito gerador é decodificada em elementos configurativos, guiando todo o processo projetual e ajudando a manutenção da coerência de linguagem.

Com base nestes estudos, torna-se claro que a diretriz para a sintaxe da forma é construída em um sistema de relações, em que estão incluídos: as possibilidades (ou restrições) oferecidas pelos materiais, tecnologia e mercado; a estrutura corpórea do usuário, bem como seus signos de representação social e códigos específicos de expressão estética.

Vale ressaltar, contudo, que, conforme Sanches et al. (2016), o projeto de design constitui um sistema permeável que se transforma constantemente na interação com o entorno sociocultural. Neste processo, as decisões se conectam umas às outras a partir de uma rede dinâmica que vai assimilando novas 
Projectar a forma: uma proposta de ferramenta metodológica para o direccionamento da sintaxe visual no design de moda,

informações e se modificando até delinear uma trajetória viável. No trajeto é essencial identificar estratégias que facilitem a gestão das variáveis projetuais, promovendo a conexão das informações e auxiliando a síntese de conceitos.

Considerando tais aspectos no universo acadêmico estudado, os procedimentos pedagógicos costumam canalizar muitas ações didáticas em prol da edificação da competência expressiva dos estudantes, com o objetivo de prepará-los para esta articulação semântica na sintaxe visual dos artefatos projetados. Para isso, as ferramentas de síntese imagética se mostram como ótimas aliadas na gestão do sistema projetual, ampliando a análise de aspectos subjetivos na experiência de uso do vestuário de moda.

Sanches e Martins (2015) ratificam que a síntese visual, por meio do emprego de imagens, auxilia a organização sistêmica do pensamento sobre a dimensão estético-simbólica do projeto e, ao mesmo tempo, é uma importante ferramenta de comunicação entre os profissionais que participam do processo de desenvolvimento de produtos, já que facilitam a visão panorâmica e a discussão sobre o processo, estimulando cada sujeito a coordenar seu domínio de ação sob o mesmo foco.

\subsection{O Pensamento Visual como Estratégia Projetual no Design de Moda}

No âmbito do design de moda, a comunicação por meio de imagens, incluindo desenhos de representação do produto e pesquisas fotográficas, pode ser utilizada em várias etapas do projeto. Sanches (2012) reforça que as ferramentas de síntese visual são essenciais ao fluxo de interações entre os elementos do sistema projetual e funcionam como meio de organização cognitiva para concretizar abstrações, facilitar a síntese de conceitos e comunicar ideias no trabalho em equipe

Motta (2010) enfatiza que as representações imagéticas são responsáveis por grande parte da viabilização do raciocínio humano. Elas consistem no principal conteúdo do pensamento, independente da "modalidade sensorial" que a gerou e de se referirem à uma coisa ou a um processo. (Damasio, 1996, p.36 apud Motta, 2010, p.120). Nesta direção, Dondis (1997) menciona uma "inteligência visual" e a capacidade humana de se comunicar em um plano não verbal. Em vista desse papel determinante da visualidade, esta autora defende a relevância de inserir, no percurso educativo profissional, a formação de um repertório para manejar a linguagem visual.

No contexto estudado, as imagens são usadas para delinear os parâmetros de sintaxe visual e indicadores de qualidades expressivas que são identificadas nas pesquisas de contextualização do universo do usuário, o qual também pode ser mapeado com a ajuda da síntese visual. Sendo assim, Sanches e Martins (2015) mapearam ferramentas que já demonstraram seu valor nas práticas didáticas do design de moda. Entre as principais ferramentas, destaca-se os painéis de síntese do cenário de inserção do produto, como o Painel de Estilo de Vida e o Mood Board de conceito de marca, assim como os de expressão emocional, como o Painel Semântico e o Painel de Tema Visual.

Por outro lado, Eppler e Burkhard (2004) investigam os benefícios do uso de representações visuais para transferência e produção de conhecimento, afirmando que a maioria das atividades cerebrais lida com o processamento e análise de imagens visuais. Conforme os autores, muitos estudos empíricos já mostraram que as representações visuais são mais eficazes que as verbais em diferentes tarefas, uma vez que a capacidade do canal de entrada de estímulos é maior quando são usadas as habilidades visuais.

Neste rumo, a utilização de mapas mentais tem sido amplamente adotada nas esferas do ensino/aprendizagem de projeto. De acordo com Buzan e Buzan (1996), esse tipo de ferramenta integra diversas estruturas cognitivas, encadeando o pensamento irradiante, o imaginativo e o estruturado, simultaneamente. Desta forma, promove a irradiação de uma ideia central em uma rede de relações, as quais são impulsionadas por estímulos associados (palavras, Imagens, esquemas gráficos, etc.) e 
sintetizadas em um espaço multidimensional que facilita uma apreensão totalizante e unificante das informações.

Pelo exposto, o uso do pensamento visual, por meio de representações gráficas, favorece a percepção de conexões simultâneas, imprimindo mais agilidade na compreensão das relações do "sistema projetual" e na associação de informações. À luz destes preceitos, sobressaem duas aplicações relevantes da síntese visual na delimitação projetual do design de moda: a gestão de informações e a expressão de referências estético-simbólicas. Estes direcionamentos serviram como plataforma da ferramenta apresentada nesta explanação.

\section{Abordagem Metodológica}

Com o intuito de estudar estratégias para a sintaxe da forma no ensino/aprendizagem de projeto diretamente no universo acadêmico do design de moda, a investigação de doutoramento tomou a forma de projeto de pesquisa na Universidade Estadual de Londrina (UEL), nomeado Incubadora de Novas Ideias: laboratório de estudo de metodologias para a sintaxe visual. A partir de análises fundamentadas em pesquisa bibliográfica, pesquisa documental e experimentações qualitativas em sala de aula, identificouse um instrumental metodológico que demonstrou bons resultados em situações projetuais diversificadas. Com base nestas constatações, foi elaborado um conjunto de ferramentas inovadoras que se destinam à gestão de informação e à expressão de conceitos de linguagem visual, das quais será detalhada apenas a que se refere à síntese expressiva, denominada Mapa de Categorias Expressivas.

Para validação das ferramentas foram realizadas interações com estudantes do Curso de Design de Moda da UEL. Sob a abordagem qualitativa da investigação etnográfica, empregou-se a observação participante em oficinas/aulas de projeto. Tendo em vista que a observação participante presume seus desdobramentos conforme realiza a aproximação com o universo pesquisado, os contatos em campo foram empregados em mais de uma etapa da pesquisa de doutoramento, uma vez que as elaborações iniciais das ferramentas exigiram a identificação de pontos críticos, a partir da observação das condutas espontâneas entre os estudantes.

As observações foram documentadas por meio de imagens fotográficas, vídeos e protocolos de observação, com registro simultâneo de observações descritivas e reflexivas, sendo distribuídas em três momentos (com grupos distintos), contando com a colaboração de 65 alunos (total) e 8 professores colaboradores.

\section{Resultados e Discussão}

O projeto Incubadora de Novas Ideias: laboratório de estudo de metodologias para a sintaxe visual realizou análises dos documentos de registro de projeto, efetuados pelos próprios alunos. Os resultados destas análises exploratórias indicaram que, no universo estudado, o uso de sínteses imagéticas como painel semântico e mood board já eram bastante valorizadas, assim como os diagramas gráficos, principalmente os mapas mentais, que têm sido cada vez mais frequentes entre as ferramentas escolhidas pelos estudantes.

Outra estratégia a ressaltar no ambiente estudado é a utilização de verbos de ação como ponto de partida para a experimentação da forma. Nas práticas criativas com a modelagem tridimensional (moulage), um verbo é tomado como impulsionador para a manipulação de possibilidades formais, estimulando a transformação de ideias. Assim, o verbo acolher, por exemplo, poderia dar impulso à várias maneiras de 
Projectar a forma: uma proposta de ferramenta metodológica para o direccionamento da sintaxe visual no design de moda,

movimentar o plano têxtil sobre o corpo e gerar diversas interpretações volumétricas, ou derivar outros verbos para experimentação, como proteger, abrigar, aconchegar, etc.

Sobre este alicerce detectou-se que algumas ferramentas metodológicas poderiam ser coordenadas, otimizando o emprego do pensamento visual na síntese de referencias para a sintaxe da forma no design de moda. Considerando os conhecimentos prévios dos estudantes, as bases teóricas da pesquisa bibliográfica e as constatações da observação participante, construiu-se os parâmetros para proposta do Mapa de Categorias Expressivas.

A referida ferramenta se aplica à síntese e comunicação de conceitos de configuração. Com ele pode-se organizar, reunir e filtrar referenciais estético-simbólicos, sintetizando uma estrutura de conexões para o enunciado visual do artefato projetado, na qual se evidencia possibilidades configurativas. Foi concebido a partir de uma combinação de técnicas, incluindo mood board, escala de diferencial semântico, verbos de ação e mapa mental.

A partir do uso de estratégias para a exploração do contexto sociocultural, os estudantes identificam códigos simbólicos que permeiam o universo usuário e são capazes de sintetizar o conceito gerador (Sanches, 2011; Sanches et al., 2016) por meio de palavras-chave que definem o verbo de ação inicial. Para impulsionar a geração de ideias é efetuada uma coleta subjetiva de imagens, quando os participantes do projeto recolhem imagens que representam a ação sugerida pelo verbo. De posse destas imagens, o próximo passo é a elaboração de um mapa mental imagético, em que se conectam representações similares e são identificadas possíveis categorias expressivas.

Para extrair elementos configurativos desta ferramenta, uma escala de diferencial semântico é aplicada para analisar as percepções sensórias (luz, temperatura, toque e gesto) de cada categoria expressiva. Para esclarecimento, uma escala de diferencial semântico mensura as reações emocionais que acompanham uma palavra, um objeto ou uma imagem. Sua utilização pode ser resumida do seguinte modo: a partir de dois descritores (adjetivos) opostos, situados nos extremos de uma escala em que se apresenta um intervalo de valores, qualifica-se as sensações provocados pelo objeto (palavra ou imagem) conforme se aproximam mais de um extremo ou outro (Osgood, Suci e Tannenbaum, 1957; Martins e Theóphilo, 2008).

Finalmente, as mensurações das percepções sensórias, resultantes do diferencial semântico, são interpretadas em cores (luz e temperatura), texturas (toque) e estruturas formais (gesto). Para melhor entendimento, as Fig.2 e Fig.3 mostram exemplos de aplicação.

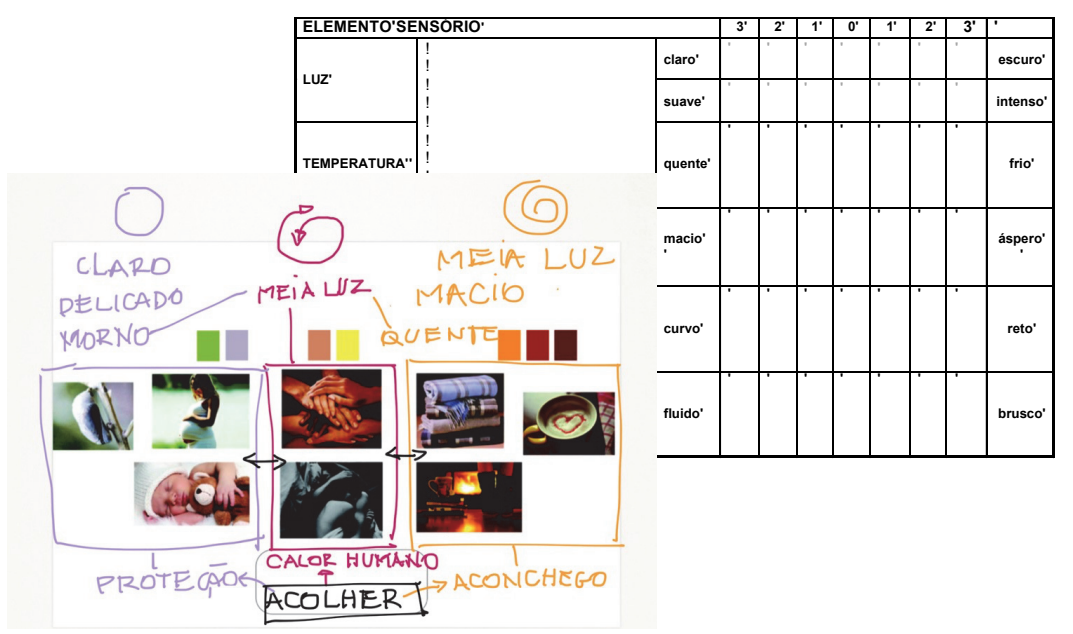

Fig. 2 Exemplo de Mapa de Categorias Expressivas. Fonte: acervo da autora (2013) 

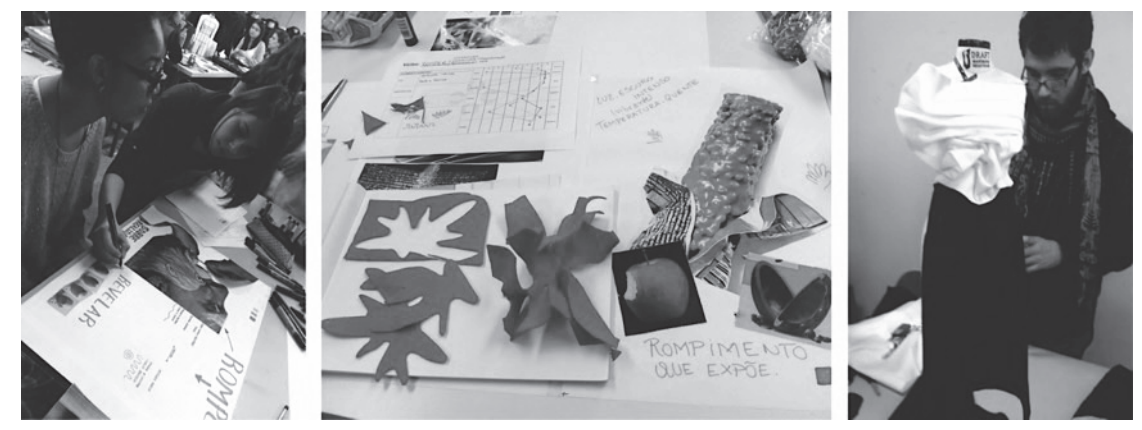

Fig. 3 Oficina de Projeto com Aplicação do Mapa de Categorias Expressivas. Fonte: acervo da autora (2013)

\section{Considerações Finais}

De acordo com Cardoso (2012), os conceitos simbólicos que são atribuídos à um objeto, em realidade não são qualidades fixas e tampouco derivam diretamente da sua configuração física, mas de um repertório cultural e de pressupostos, ou seja, o significado é construído pela integração da percepção humana, com o tempo, o espaço, a cultura e a memória. Não obstante, mesmo que a interpretação esteja circunstanciada por repertórios individuais e o contexto, as percepções de sentido provocadas pelo artefato se efetivarão apenas se o suporte formal/visual estiver organizado de modo a estimular associações peculiares aos universos em que transitam os usuários interpretadores.

Neste rumo, o Mapa de Categorias Expressivas possibilita o direcionamento dos elementos sintáticos de modo integrado e pertinente. Igualmente, promove a comunicação entre os participantes do projeto e facilita as iniciativas de design colaborativo, uma vez que o usuário pode ser incluído na elaboração do mapa mental imagético.

Ainda que os resultados se refiram às aplicações no universo acadêmico do design de moda, as mesmas estratégias poderiam ser estendidas a outras experimentações, visto que as ferramentas de síntese visual favorecem a percepção de conexões simultâneas e, como meio de organização cognitiva, facilitam a expressão de abstrações e a síntese de conceitos.

Ressalta-se que o Mapa de Categorias Expressivas foi adotado no ambiente pesquisado, depois das validações efetuadas por intermédio de análises comparativas, auto avaliações dos estudantes e avaliações dos professores colaboradores que participaram do estudo. Entretanto, percebe-se que para a evolução destas novas abordagens, a organização curricular do curso em questão pode ser fator de influência, já que o seu projeto pedagógico promove a flexibilidade de planejamento e a integração das unidades curriculares na prática projetual. Finalmente, sob o rumo da gestão sistêmica do projeto e do pensamento visual, espera-se avançar na busca por melhores práticas educacionais para o desenvolvimento do raciocínio projetual entre estudantes de design de moda.

\section{Referências}

BUZAN, T., BUZAN, B. (1996). The Mind Map Book: How to Use Radiant Thinking to Maximize Your Brain's Untapped Potential. New York: Penguin Putnam Inc.

COUTO, R. M. S., FARBIARZ, J., NOVAES, L. (2014). Gustavo Amarante Bomfim: uma coletânea. Rio de Janeiro: Rio Books.

CARDOSO, R. (2012). Design para um mundo complexo. São Paulo: Cosac Naify.

CASTILHO, K. (2004). Moda e linguagem. São Paulo: Universidade Anhembi Morumbi. 
Projectar a forma: uma proposta de ferramenta metodológica para o direccionamento da sintaxe visual no design de moda,

COELHO, L. A. (2008). Conceitos-chave em design. Rio de Janeiro: Ed. PUC-Rio \& Novas Ideias.

DONDIS, A. (1997). Sintaxe da Linguagem Visual. São Paulo: Martins Fontes.

EPPLER, M. J., BURKHARD, R. A. (2007). "Visual representations in knowledge management: framework and cases" em Journal of Knowledge Management, v.11, 4, pp.112-122. Bingley: Emerald $<$ http://www.emeraldinsight.com/doi/full/10.1108/13673270710762756>[Acesso: 20 julho de 2014].

GOMES FILHO, J. (2006). Design do objeto: bases conceituais. São Paulo: Escrituras.

KRIPPENDORFF, K. (1989). On the Essential Contexts of Artifacts or on the Proposition That "Design Is Making Sense (Of Things)" em Design Issues, v. 5, n. 2, p. 9-39. Cambridge: The MIT Press $<$ http://www.jstor.org/stable/1511512> [Acesso: 15 de julho de 2012].

LESSA, W. D. (2009). "Linguagem da forma/linguagem visual no âmbito do ensino de design: balizamentos teóricos; tópicos de pesquisa" em Arcos Design. Rio de Janeiro: ESDI-UERJ, ano 4, n.2, p. 69-91. <http://www. esdi.uerj.br/arcos> [Acesso: 15 julho de 2012].

MARTINS, G. A., THEÓPHILO, C.R. (2009). Metodologia da Investigação Científica para Ciências Sociais Aplicadas. São Paulo: Atlas.

MONTEMEZZO, M. C. F. S. (2003) Diretrizes Metodológicas para o Projeto de Produtos de Moda no Âmbito Acadêmico. Dissertação (Mestrado Des. Industrial). Bauru : UNESP, <http://www.faac. unesp.br/Home/PosGraduacao/Design/Dissertacoes/maria_celeste_montemezzo.pdf>

MONTEMEZZO, M.F. S., SANTOS, J. G. (2002) "O papel do vestuário na interação homem-ambiente" em Proceedings $5^{\circ} \mathrm{P} \& D$ Design Congress. Rio de Janeiro: AEND-BR. p. 1-10

MOTTA, L.C. (2010). "Estruturas Semióticas do Conhecimento e Neurociência no Design Instrucional" em Nojima, V., Almeida Jr. Design, Comunicação e Semiótica: Estudo e pesquisa das relações transversais. Rio de Janeiro: $2 \mathrm{AB}$, p. $60-76$

MUNARI, B. (2006). Design e Comunicação Visual. São Paulo: Martins Editora.

NIEMEYER, L. (2003). Elementos de semiótica aplicados ao design. Rio de Janeiro: 2AB.

OLIVEIRA, S. R. (2007). Moda também é texto. São Paulo: Rosari.

OSGOOD, C.E., SUCI, G., TANNENBAUM, P. (1957). The measurement of meaning. Urbana, IL: University of Illinois Press.

SALTZMAN, A. (2008) "O design vivo" en PIRES, D. Design de Moda: olhares diversos. Barueri, SP: Estação das Letras e Cores Editora. p. 305-318.

SANCHES, M.C.F. (2012). "Projetando o Intangível: as ferramentas da linguagem visual no design de moda" em Martins, R. F., Van Der Linden, J. C. Pelos caminhos do design: metodologia de projeto. Londrina: EDUEL. p. 395415 .

SANCHES, M. C. F. (2011) "Uma análise da delimitação projetual no design de moda" em VI CIPED Congresso Internacional de Pesquisa em Design. Lisboa: CIAUD. p. 1-5

SANCHES, M. C. F., MARTINS, S. R. M. (2015) "Projetando mensagens visuais: a contribuição das ferramentas de síntese imagética no design de moda" em Estudos em Design, v. 23, n. 1, p. 108-117. $<$ https://estudosemdesign.emnuvens.com.br/design/article/view/200/177> [Acesso: 20 abril de 2015].

SANCHES, M. C. F., HERNANDIS ORTUÑO, B., MARTINS, S. R. M. (2015) " Fashion design: the project of the intangible" em Procedia Manufacturing, v. 3, 2015, p. 2311-2317, < http:// www.sciencedirect.com/science/article/pii/S2351978915003789>

SANCHES, M. C. F., BARBOSA, T. M., HERNANDIS, B., MARTINS, S. M. (2016). "Bases para o ensino/aprendizagem de projeto no design de moda: conectando diretrizes didáticas e estratégias metodológicas" em ModaPalavra. Florianópolis: UDESC, v.17, n.9, p.119-144. < http://revistas. udesc.br/index.php/modapalavra/article/view/1982615x08172016119/4764>[Acesso: 20 jan. de 2016]

SOUZA, P. M. (2008) "A moulage, a inovação formal e a nova arquitetura do corpo" em Pires, D. Design de Moda: olhares diversos. Barueri, SP: Estação das Letras e Cores Editora. p. 327-345. 